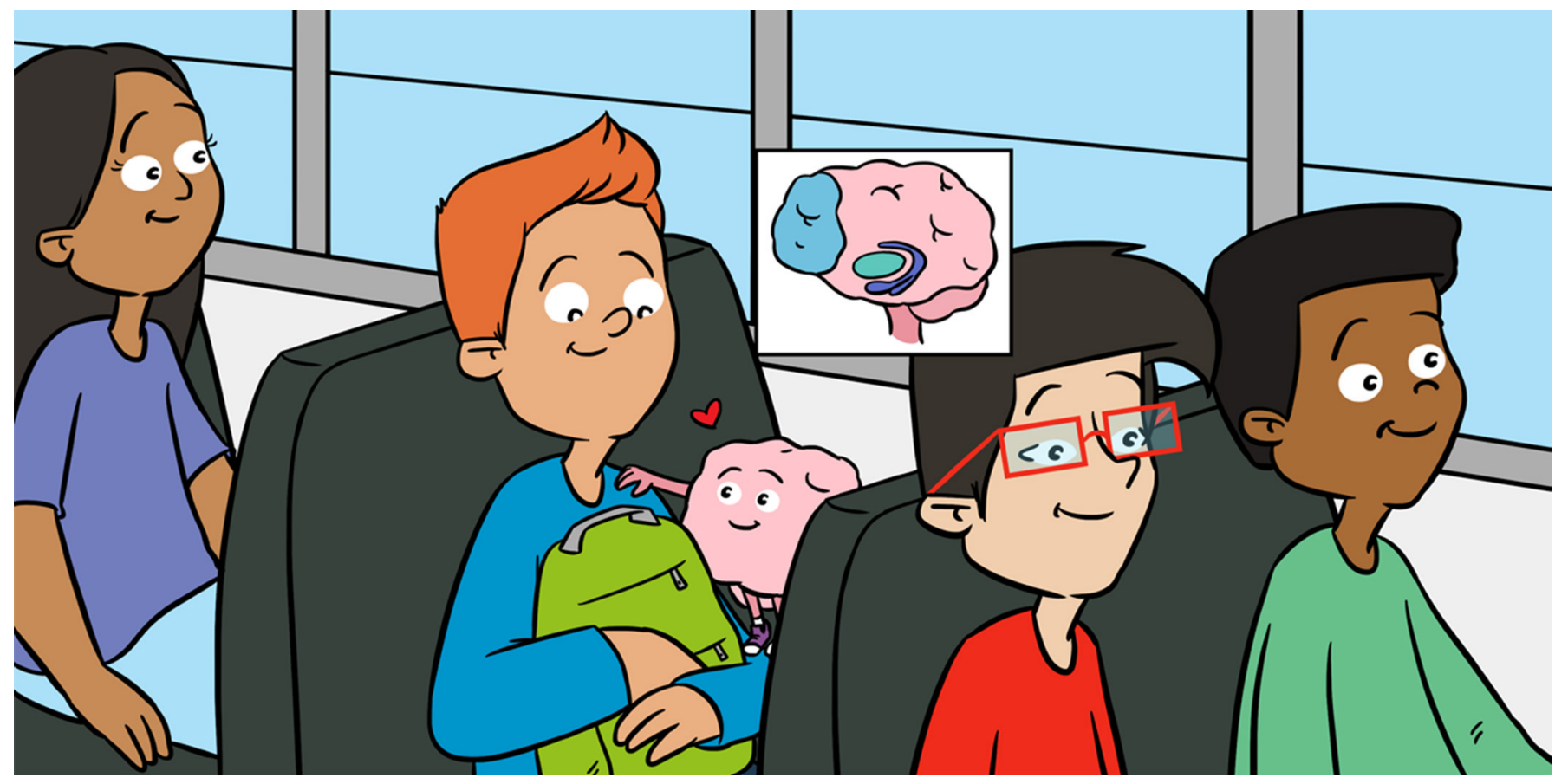

\title{
RACISM ON THE BRAIN
}

\section{Claire Weichselbaum ${ }^{1 *}$ and Kira Hudson Banks ${ }^{2}$}

${ }^{1}$ Neuroscience Program, Division of Biology and Biomedical Sciences, Washington University in St. Louis, St. Louis, MO, United States

${ }^{2}$ Department of Psychology, Saint Louis University, St. Louis, MO, United States

YOUNG REVIEWERS:

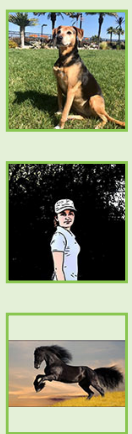

ETHAN

AGE: 11

MARILIA

AGE: 13

JAIDEN

AGE: 14

\section{RACISM}

Treating someone unfairly because of their skin color (individual racism) and a system of rules and practices that treat people unfairly because of their skin color (institutional racism).
Racism continues to be a significant problem in much of the world. Understanding how racism happens in the brain may help us find ways to overcome it. Our brains often categorize people as similar to, or different from, ourselves. A part of the brain called the amygdala becomes active when we see someone who we think is different, and this can lead to treating that person unfairly. But another part of the brain called the prefrontal cortex is able to calm the amygdala, and we can boost its power using a thinking strategy called cognitive reappraisal. Even better, we may be able to prevent people from becoming racist by teaching kids to appreciate differences, so their amygdala does not get activated by people different from themselves. Combined with fixing unfair rules and systems around us, these brain strategies may help us to defeat racism.

When you hear about racism in the news, or see racist things happening in your community, you might wonder... can't we just 
Figure 1

A cartoon illustrating intergroup bias-Player 3 sees the red team as his in-group and the blue team as his out-group, so he shows a bias in favor of the red team and against the blue team. (If we were considering Player 17's perspective, the in-group and out-group would be reversed). Image adapted from macrovector; text based on Cikara and Van Bavel [1].

1 In fact, this question was recently asked by six-year-old Kyle from New York, who wants to be a neurosurgeon when he grows up. Thanks for inspiring this article, Kyle!

\section{INTERGROUP BIAS}

The brain's tendency to categorize people as similar to you (in-group) or different from you (out-group), and to treat in-group people better than out-group people.

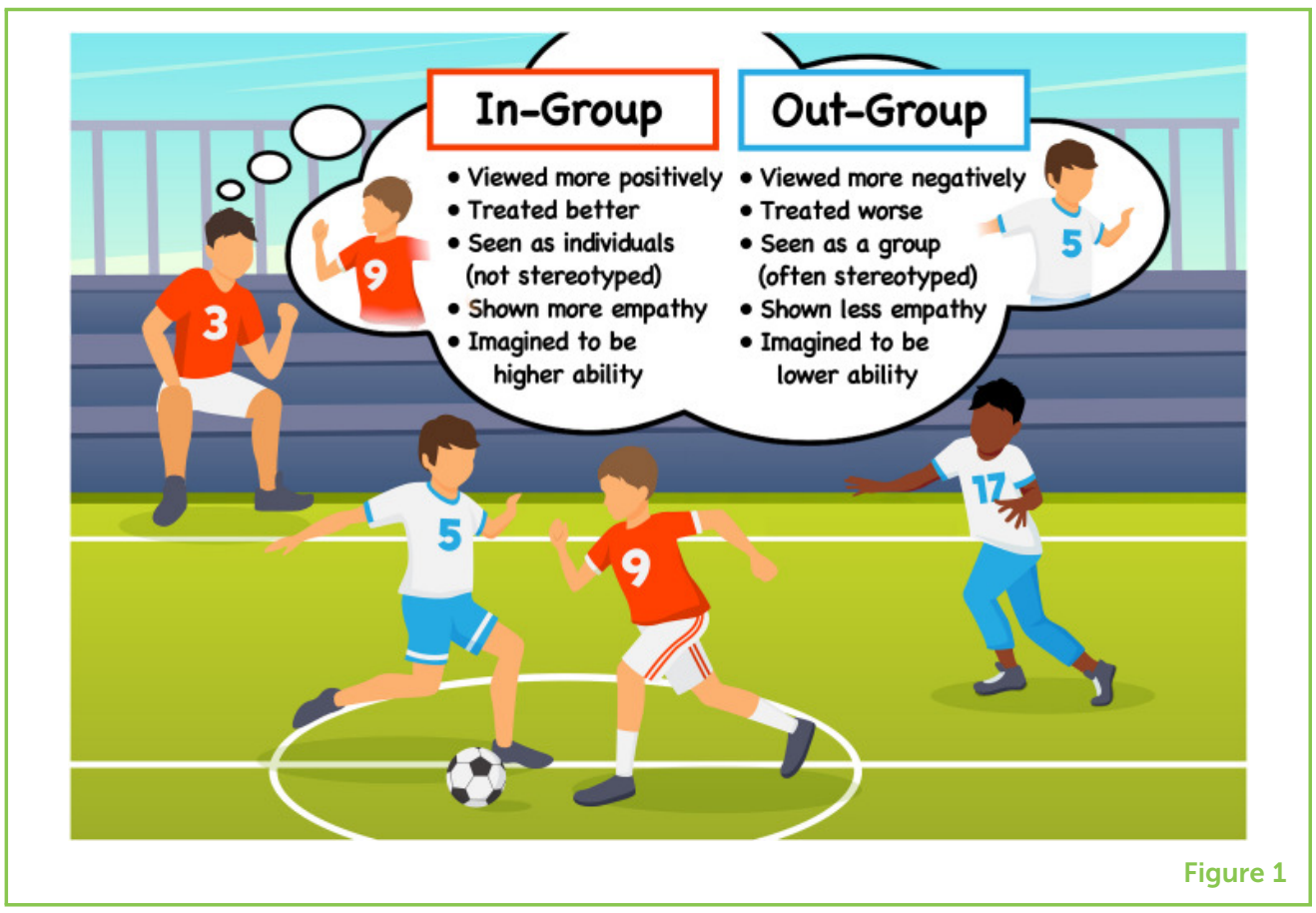

remove the racism from the brains of those racist people? ${ }^{1}$ Unfortunately, it's not that simple. Racism does not come from a single part of the brain-it arises from many parts of the brain working together and interacting with the world. The good news is, there are scientists studying how this happens and how we might be able to help brains become less racist, or even prevent racism from occurring in the first place.

\section{IN-GROUPS AND OUT-GROUPS}

Brains are really good at putting things into categories. Sometimes this is useful, like when you are a baby and you need to learn the difference between dogs and cats, or things that are safe to eat and things that are yucky. But it can become a problem when brains use those same automatic systems to put people into categories too. Brains especially like to put people into the categories of "people like me" and "people different from me"-the scientific name for those categories are "in-group" and "out-group." And often, our brains tell us to be nicer to the in-group people than the out-group people [1]. This is called intergroup bias. For example, if you are on a sports team, you are probably going to cheer for the people on your own team more than the people on the other team, right? That's because your brain has put the people on your team in your in-group category (Figure 1).

Of course, cheering for your sports team is not a problem. But it could become a problem if you started being mean to people on the other team, or if you started thinking that the people on your team are better 


\section{Figure 2}

A diagram of the brain showing the amygdala, which becomes activated in response to seeing members of the out-group, and the prefrontal cortex, which regulates the amygdala.

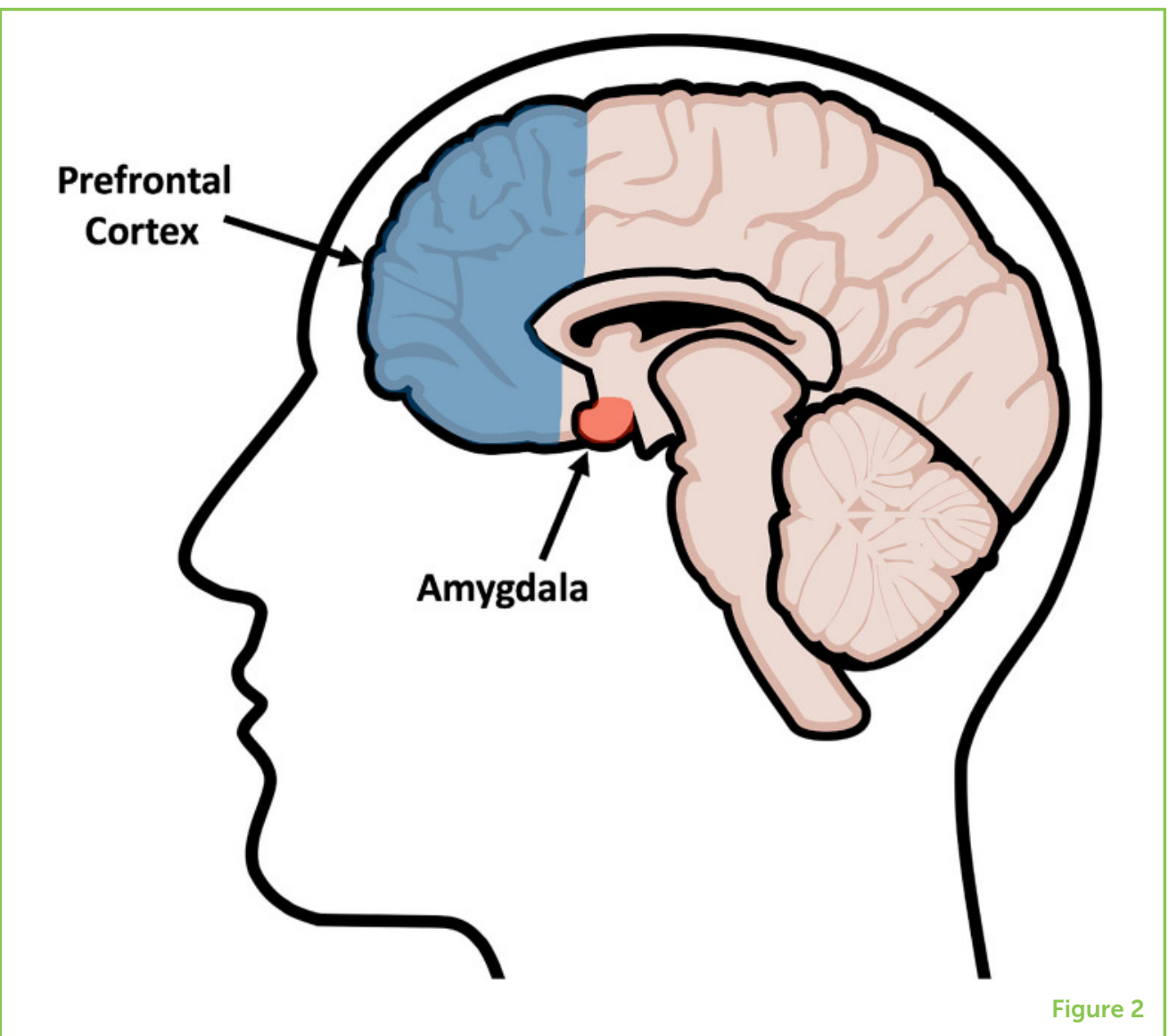

than everyone else. It would be even worse if your city made up rules saying your team could go certain places that the other team was not allowed to, or if people started making movies and commercials that suggested players on the other team were bad people.

And that is exactly what happens with racism. Seeing differences is not a problem-in fact it's great to notice all the wonderful variety of skin tones and hair textures! Wouldn't it be boring if we were all the same? But it is a problem when people in power put others who look like them in their in-groups and create rules that treat those in other groups unfairly. For example, in many parts of the world, people with lighter skin tones have a history of making rules that discriminate against people with darker skin tones. Just like being mean to people on the other sports team, but much worse, because your skin color is something you can't change. Your skin is something you are born with and a beautiful part of who you are, not just something you can take on and off like a sports jersey!

\section{WHO'S WHO IN THE BRAIN}

What happens inside the brain when we sort people into in-group and out-group categories? (Figure 2). Scientists have discovered that a tiny 


\section{AMYGDALA}

A small area of the brain involved in processing emotions and, among other things, responding to people who are categorized as members of

the out-group

2 Wondering how scientists measure activation in the brain? Check out another great Frontiers for Young Minds article to find out: https://kids. frontiersin.org/article/ 10.3389/frym.2019. 00086

\section{PREFRONTAL}

CORTEX

An area at the front of the brain involved in planning, decision-making, and self-control, including regulating the amygdala out-group response.

\section{COGNITIVE}

\section{REAPPRAISAL}

A technique that can be used to help regulate emotions by changing the way you think about a situation. part of the brain called the amygdala becomes activated ${ }^{2}$ when we see someone in the out-group, someone we consider different from ourselves [2]. Some scientists think this is because we view people in the out-group as scary, or a threat, even when they really are not [3], while other scientists think the amygdala is just good at detecting anything new or unfamiliar [1]. The amygdala is involved in lots of other important things too, like processing our emotions, so we can't just get rid of it to solve racism!

But scientists have also found that another part of the brain seems to have the job of calming down the amygdala, including the amygdala's response to out-group people [4]. That calming-down part is called the prefrontal cortex - it is the area of your brain at the very front of your head (if you put your hands on your forehead, your prefrontal cortex is right underneath). When people do racist things, it may mean that their prefrontal cortex is not doing a very good job of regulating their amygdala. So, could we help the prefrontal cortex do its job better?

\section{BOOSTING THE PREFRONTAL CORTEX}

In fact, there are some studies suggesting that we can help the prefrontal cortex do its job better! Think about it this way: have you ever felt really angry at someone and wanted to punch them, but then you stopped yourself? Or have you ever watched a scary movie and wanted to run away, but then you remembered you were actually safe? Those are examples of your amygdala reacting, and then your prefrontal cortex calming it down so you can act the way you really want to instead of automatically following the amygdala's instructions.

The same thing happens when someone's amygdala reacts to an out-group person and their prefrontal cortex calms it down. It is like the amygdala says, "hey, that person is different, so maybe they are a threat!" and the prefrontal cortex says, "no, they are different but that is okay!" (Of course, the amygdala and prefrontal cortex can't actually talk, but those are the kinds of signals they are sending to each other inside your brain). Remember, just because your amygdala makes a big deal out of something, that does not mean it is right or that you have to listen to it!

We know that if you remind yourself of certain things while you watch a scary movie-things like "it's just a movie, it's not real, I am safe" -this helps your prefrontal cortex do its job better. Scientists call that cognitive reappraisal, essentially just changing how you think about a situation. We know that cognitive reappraisal works by boosting the powers of the prefrontal cortex, so it can do a better job of calming down the amygdala [5]. So, could we use a similar strategy 


\section{STEREOTYPES}

An over-generalized belief or expectation about people who belong to a particular group, such as people who share the same skin color

\begin{abstract}
What is race?
Scientists today consider race to be a social construct-a made-up label not based on scientific facts. Differences that appear to be related to race, like who gets a better education or who gets higher-paying jobs, are actually caused by people being treated differently and denied opportunities based on their skin color. Having darker skin just means that your ancestors came from a warmer place, where their skin needed to protect them from the sun; lighter skin means your ancestors came from a colder place, where their skin needed to let in more sunlight. The stereotypes that many people have about different skin tones are the result of lighter-skinned people treating darker-skinned people unfairly for so long that it is created a pattern, which our brains notice whether we want them to or not-and this can make it harder to get rid of racist intergroup bias, if we are not actively paying attention and working against it!
\end{abstract}

to help the prefrontal cortex work better in someone's brain to stop their racism?

\section{BUILDING A LESS RACIST BRAIN}

A few studies have tried using cognitive reappraisal and similar strategies to reduce racism. For example, when scientists in the United States showed White people pictures of Black people who they already liked, or encouraged them to think about Black people as individuals rather than as one big group, the White people showed less amygdala activation [6]. Also, grouping people into mixed-race teams changed their amygdala activation in an interesting way-the amygdala reacted based on the assigned teams rather than racial groups, suggesting it may be possible to reduce racism just by helping White people think of Black people as part of their in-group [1].

But the downside is, these effects did not last very long [2]. After people stop using cognitive reappraisal, they return to their old ways of thinking. So what can we do to help brains become less racist for good?

It seems that people who really want to become less racist are better at using strategies like these all the time, even without realizing it [6]. So teaching people about racism, and making them feel motivated to stop it, may help them activate their prefrontal cortex more effectively. That includes helping people understand that the whole idea of "race" was made up by White people who wanted power and control-there is really no reason for it to define our in-groups and out-groups at all! [7].

\section{A FUTURE WITHOUT RACISM?}

A few years ago, some scientists had a brilliant idea. They realized that all these studies about racism in the brain had been done with 
Figure 3

(A) A scatterplot showing the relationship between age and amygdala response to pictures of Black people. As kids get older, they show more amygdala activation. (B) A scatterplot showing the relationship between diversity of friends and amygdala response to pictures of Black people. Kids and teens with a more diverse friend group had less amygdala activation, regardless of age. Adapted from Telzer et al. [8], reprinted courtesy of The MIT Press.
A
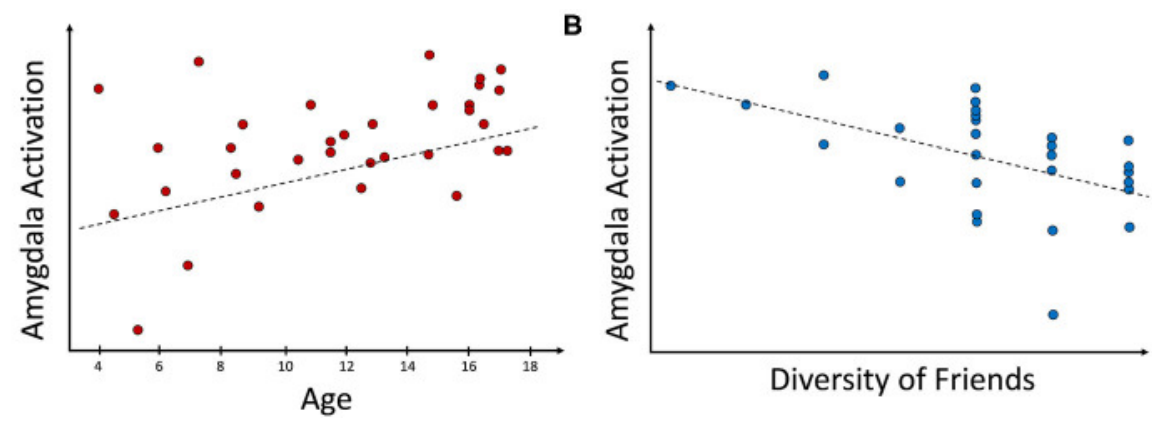

Figure 3

grownups, and they wondered, what if we studied the brains of kids instead?

Guess what they discovered? Unlike grownups, the amygdala in kids' brains does not react differently to people based on their skin color! Kids notice skin color of course, but it seems like their brains don't start using skin color to assign people to the in-group or out-group until they get older (Figure 3A) [8]. And the coolest part? Kids and teens with more diverse groups of friends had a less reactive amygdala regardless of their age (Figure 3B) [8]. It's like their brains realized that there is no reason to divide people into in-group and out-group categories by skin color, since they already had lots of friends with different skin colors.

This discovery tells us that racism is learned-our brains do not automatically have to assign people to in-group and out-group categories by skin color. We can appreciate differences instead of using them to divide us. And that is good news, because it means that while we all have the potential to become racist, we also have the potential to create a future where no one is racist at all. Studies like this can help us find ways to surround young brains with conditions that prevent racism rather than contribute to it, so over time we might be able to get rid of racism altogether.

However, it is important to remember that racism does not just happen inside the brain. Racism is also built into the many unfair rules and systems created by biased brains, often maintained by people who do not even realize they are contributing to the problem. Even if someone does not mean to be racist, they might still be following unfair rules that have racist consequences for others. So as we work toward ending racism in the brain, we must also work toward ending racism around us [4]. As we fix these rules and systems, our brains will notice new patterns in how people are treated, which may help to further reduce intergroup bias-moving us closer to a fair and equitable world both inside and outside our heads. 


\section{REFERENCES}

1. Cikara, M., and Van Bavel, J. J. 2014. The neuroscience of intergroup relations. Perspect Psychol. Sci. 9:245-74. doi: 10.1177/1745691614527464

2. Kubota, J. T., Banaji, M. R., and Phelps, E. A. 2012. The neuroscience of race. Nat. Neurosci. 15:940-8. doi: 10.1038/nn.3136

3. Chekroud, A. M., Everett, J. A. C., Bridge, H., and Hewstone, M. 2014. A review of neuroimaging studies of race-related prejudice: does amygdala response reflect threat? Front. Hum. Neurosci. 8:179. doi: 10.3389/fnhum.2014.00179

4. Firat, R. B. 2019. Opening the "Black Box": functions of the frontal lobes and their implications for sociology. Front. Sociol. 4:3. doi: 10.3389/fsoc.2019.00003

5. Öner, S. 2017. Neural substrates of cognitive emotion regulation: a brief review. Psychiatry Clin. Psychopharmacol. 28:91-6. doi: 10.1080/24750573.2017.14 07563

6. Senholzi, K. B., and Kubota, J. T. 2016. "The neural mechanisms of prejudice intervention," in Neuroimaging Personality, Social Cognition, and Character, eds John R. Absher and Jasmin Cloutier. Academic Press p. 337-54. doi: 10.1016/B978-0-12-800935-2.00018-X

7. Kurzban, R., Tooby, J., and Cosmides, L. 2001. Can race be erased? Coalitional computation and social categorization. Proc. Natl. Acad. Sci. 98:15387-92. doi: $10.1073 /$ pnas. 251541498

8. Telzer, E. H., Humphreys, K. L., Shapiro, M., and Tottenham, N. 2013. Amygdala sensitivity to race is not present in childhood but emerges over adolescence. J. Cogn. Neurosci. 25:234-44. doi: 10.1162/jocn_a_00311

SUBMITTED: 21 September 2020; ACCEPTED: 19 July 2021; PUBLISHED ONLINE: 25 August 2021.

EDITED BY: Ryan E. B. Mruczek, College of the Holy Cross, United States

CITATION: Weichselbaum C and Banks KH (2021) Racism on the Brain. Front. Young Minds 9:608843. doi: 10.3389/frym.2021.608843

CONFLICT OF INTEREST: The authors declare that the research was conducted in the absence of any commercial or financial relationships that could be construed as a potential conflict of interest.

COPYRIGHT @ 2021 Weichselbaum and Banks. This is an open-access article distributed under the terms of the Creative Commons Attribution License (CC BY). The use, distribution or reproduction in other forums is permitted, provided the original author(s) and the copyright owner(s) are credited and that the original publication in this journal is cited, in accordance with accepted academic practice. No use, distribution or reproduction is permitted which does not comply with these terms. 

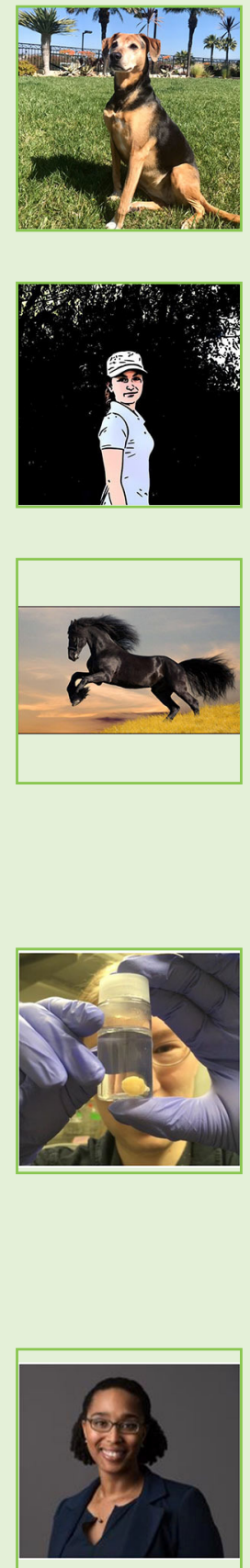

\section{YOUNG REVIEWERS}

\section{ETHAN, AGE: 11}

I am fascinated by all topics in STEM, especially 3D-printing, robotics, and astronomy. My hobbies include Legos, playing card games, learning magic tricks, and watching the Office on Netflix.

\section{MARILIA, AGE: 13}

Hi! My name is Marilia. I am 13 years old, live in Germany and like ice skating and rythmic gymnastics. I have a small dog which I love! One day I would like to travel to Australia and see the coalas. I enjoy to be with my friends and go swimming or watch a film with them.

\section{JAIDEN, AGE: 14}

I have been interested in science since age 7. My favorite journal to read is Scientific American. My academic interests include chemistry, economics, and entrepreneurship. My hobbies include equestrian show jumping, playing board and card games, puzzles and riddles.

\section{AUTHORS}

\section{CLAIRE WEICHSELBAUM}

I am a researcher and science educator who firmly believes that science can change the world! I recently finished my Ph.D. in neuroscience at Washington University in St. Louis, where I studied how brains process social information-both human brains and mouse brains (like the one in this photo). When I am not in the lab, I can usually be found sharing my love of science with kids of all ages. In my spare time, I also enjoy playing board games, fostering cats, and attempting to ride a unicycle. ${ }^{*}$ cweichselbaumawustl.edu

\section{KIRA HUDSON BANKS}

I am a mother of two kids, ages 11 and 14, who I love more than anything. They think I am a boring mom until they see me in a magazine or hear my podcast, Raising Equity. I enjoy researching and talking about how people think about themselves (their identity) and how that shapes their experiences of discrimination. I like to work with groups to be more equitable and fair so that everyone can be fully who they are. I am a professor of psychology and Co-Founder of the Institute for Healing Justice and Equity at Saint Louis University. 